\title{
Strengthening Induced by Grain Boundary Solute Segregations in Ultrafine-Grained and Nanocrystalline Alloys: a Brief Review
}

\author{
S.V. Bobylev ${ }^{1}$ and A.G. Sheinerman ${ }^{1,2}$ \\ ${ }^{1}$ Institute of Problems of Mechanical Engineering, Russian Academy of Sciences, St. Petersburg 199178, Russia \\ ${ }^{2}$ Saint Petersburg State University, 7/9 Universitetskaya nab., St. Petersburg 199034, Russia
}

Received: February 18, 2020

\begin{abstract}
The experimental data, computer simulations and analytical models describing strengthening mechanisms acting in nanocrystalline and ultrafine-grained alloys containing grain boundary solute segregations are briefly reviewed. We demonstrate the important role of grain boundary solute segregation in strength enhancement of ultrafine-grained alloys. We show that these segregations allow reaching yield strength exceeding one predicted by the Hall-Petch dependence. Available experimental and theoretical data indicate that strengthening induced by grain boundary solute segregations is achieved by either suppressing dislocation emission from GBs or hampering dislocation slip through grain interiors.
\end{abstract}

Nanocrystalline and ultrafine-grained metals and alloys are the subject of intensive scientific research as they often demonstrate outstanding mechanical properties [1-8]. It is known that the yield strength is related to the mean grain size via the classic Hall-Petch relationship (see recent reviews [9-13]). Over past decade a number of ultrafine-grained (UFG) and nanocrystalline (NC) alloys have been engineered [14-20] using severe plastic deformation (SPD) that exhibit considerably higher strength than the Hall-Petch relationship predicts. The nature of this enhanced strength is a matter of debate. It is often attributed, in particular, to the experimentally detected [14-22] segregations of solute elements at grain boundaries (GBs). In this work we briefly review recent experimental and theoretical data concerning this enhanced strength of UFG and N alloys containing GB solute segregations.

Authors of experimental works [16-19] reported ultra-high strength close to $1 \mathrm{GPa}$ for the SPD-processed $\mathrm{Al}$ alloys 1570, 5083, 7475, and 7075. For example, in the $\mathrm{Al}$ alloy 1570 with a mean grain size of $100 \mathrm{~nm}$, the yield strength is approximately $200 \mathrm{MPa}$ higher than the HallPetch relationship predicts for an alloy with the same grain size and chemical composition (Fig. 1 [16]). Dotted line in Fig. 1 shows projected Hall-Petch dependence for Al alloy 1570 (for details, see [16]). The common feature that all these alloys share is the formation of segregations of solute atoms at GBs [14-19]. Fig. 2a shows atom probe tomography image of $\mathrm{Al}$ alloy 5083 specimen [17]. $\mathrm{Mg}$ atoms segregations are observed at certain locations on the grain boundaries (Fig. 2b), which is believed to be the reason of these $\mathrm{Al}$ alloys excellent strength.

Strength enhancement attributed to solute segregations at GBs has also been documented in coarse-grained [23] and UFG [14,18-20] carbon steels, a nanocrystalline TWIP steel [22], an UFG Al-Mg-Si alloy [21], as well as in nanocrystalline $\mathrm{Cu}$ alloys [24-26], an $\mathrm{Al}-\mathrm{Cu}$ alloy [27] and $\mathrm{Cu}-\mathrm{Ta}$ alloy [28]. The underlying mechanisms of this segregation-induced strength enhancement remain a matter of debate.

For example, Zhang et al. [26] measured a considerable increase in hardness, tensile ductility and fatigue lifetime of nanocrystalline $\mathrm{Cu}$ thin films after the addition of $\mathrm{Zr}$. Experimental results showed that the $\mathrm{Cu}-0.5$ at. $\% \mathrm{Zr}$ film exhibited the highest hardness, largest duc-

Corresponding author: S.V. Bobylev, e-mail: bobylev.s@gmail.com 


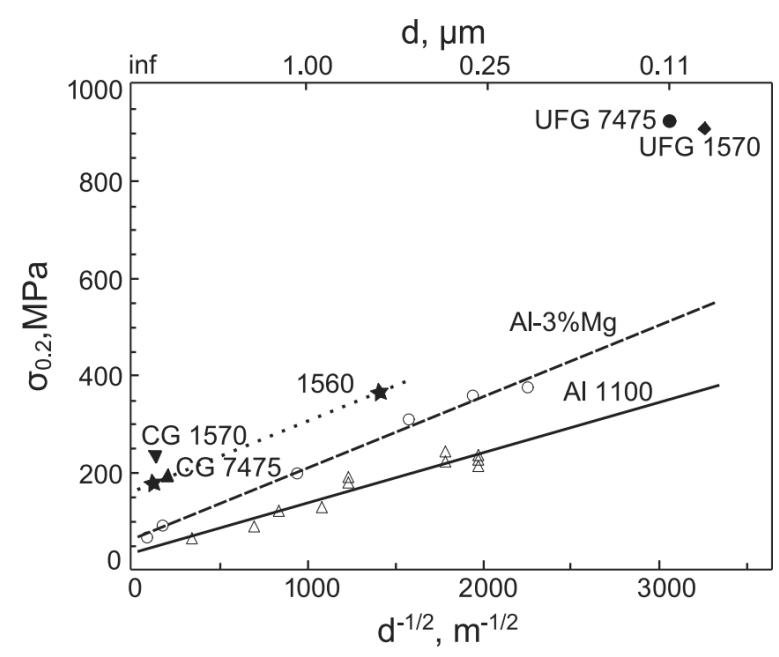

Fig. 1. The Hall-Petch relation for the $\mathrm{Al}$ alloys: 1100, $\mathrm{Al}-3 \% \mathrm{Mg}$ and data on the yield stresses of Al alloys: 1560, 1570, 7475. Dotted line is the projected Hall-Petch relation for 1570 alloy. Reproduced from [16] with permission. Copyright (2010), Elsevier.

tility and longest fatigue lifetime, which are increased by $120 \%, 80 \%$, and above an order of magnitude, respectively, in comparison with its pure $\mathrm{Cu}$ counterpart. They found that at 0.5 at.\% $\mathrm{Zr}$ content the film exhibited the yield strength of $1600 \mathrm{MPa}$, while the combined effect of the GB and nanotwin strengthening predicted the yield strength of $1100 \mathrm{MPa}$. They attributed the discrepancy to the formation of GB Zr segregations. They suggested that $\mathrm{Zr}$ segregation at GBs significantly reduce the GB energy, which suppresses GB migration and other GB activities and hence increases the strength.

Chang and Hong [29] and Valiev et al. [16] assumed that segregation-induced strengthening is associated with a decrease in the activation volume for plastic flow experimentally documented [29] in a Zr-Nb alloy after the addition of sulfur segregated along GBs. They defined this activation volume $V_{a}$ as:

$V_{a}=k T \partial \ln \dot{\gamma} / \partial \tau=n k T \ln (\dot{\varepsilon})_{1} /(\dot{\varepsilon})_{2} /\left(\sigma_{1}-\sigma_{2}\right)$,

where $\tau$ is the shear stress, $n$ is the Taylor factor (taken equal to 4$), k$ is the Boltzman constant, $\dot{\gamma}$ is the shear strain rate, $\sigma_{1}$ and $\sigma_{2}$ are the applied shear stresses at the normal strain rates $(\dot{\varepsilon})_{1}$ and $(\dot{\varepsilon})_{2}$. Experiments showed that the activation volume $V_{a}$ decreased from $110 b^{3}$ to $80 b^{3}$ where $b$ is the Burgers vector with the addition of 300 ppm sulphur at room temperature. Chang and Hong [29] discussed actual mechanisms leading to the decrease of activation volume and suggested that sulfur atoms pin segments of dislocations emitted from GBs thus affecting the activation length of dislocations. But no numerical model allowing calculating the effect on yield strength was suggested.

Borovikov et al. [30] suggested that segregationinduced strength enhancement is associated with a decrease of the number of active GB dislocation sources. Their suggestion is based on the results of their computer simulations of deformation of nanocrystalline $\mathrm{Ag}$ containing GB $\mathrm{Cu}$ segregations [30]. The simulations revealed that the yield strength of nanocrystalline $\mathrm{Ag}$ (containing $\mathrm{GB} \mathrm{Cu}$ segregations) first increases and then decreases with an increase in $\mathrm{Cu}$ concentration (Fig. 3) and demonstrated the existence of GB and triple junction dislocation sources. The simulations also showed that a part of these sources (that could be treated as GB and triple junction dislocation segments) is pinned (deactivated) by $\mathrm{Cu}$ segregations. Since some favorable dislocation sources are inactive, dislocations are emitted from less favorable sources (activated at a higher stress), which results in an increase in the yield strength of the nanocrystalline solid. At the same time, at high enough average $\mathrm{Cu}$ concentration, the concentration of $\mathrm{Cu}$ in $\mathrm{Cu}$ segregations located at dislocation sources

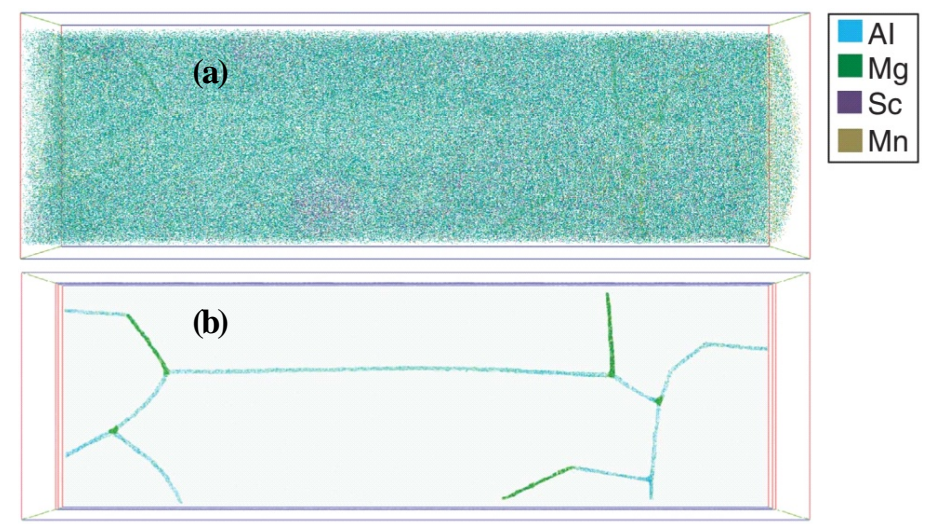

Fig. 2. (a) Atom probe tomography image of NH-5083 alloy. (b) The image revealing the grain-boundary locations in a thin 1-nm-thick slice of data. Solute segregations are observed at certain locations on the grain boundaries. Reproduced from [17] with permission. Copyright (2010), Macmillan Publishers Limited. 


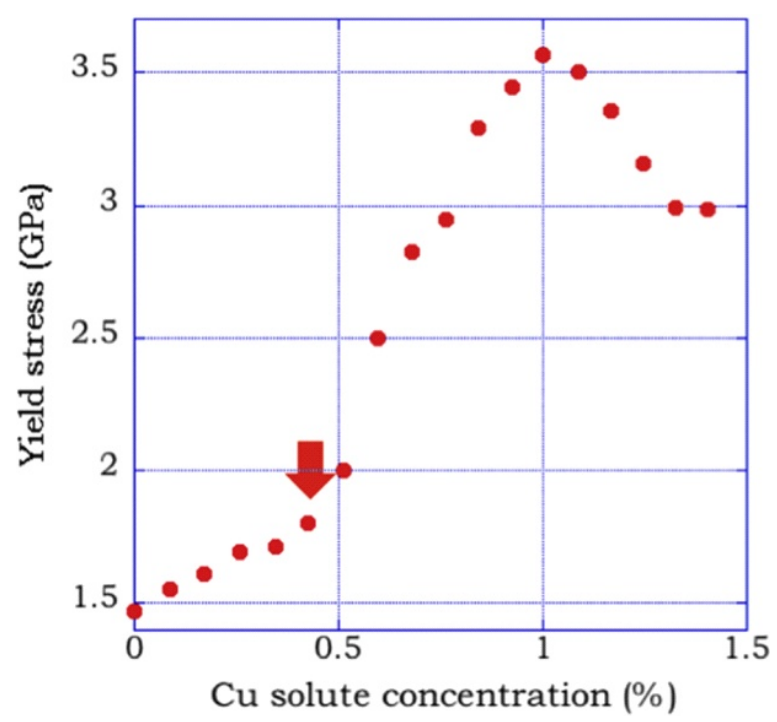

Fig. 3. The dependence of the yield stress of the $\mathrm{Ag}-\mathrm{Cu}$ alloy on solute concentration (at.\%). Reproduced from [30] with permission. Copyright (2018), Elsevier.

also becomes very high, resulting in the creation of very high elastic stresses at segregation boundaries. These stresses appear to be sufficiently high to induce dislocation nucleation at segregation boundaries, which serve as new dislocation sources. The formation of new segregation-induced dislocation sources reduces the yield strength of nanocrystalline $\mathrm{Ag}-\mathrm{Cu}$ alloys at high $\mathrm{Cu}$ concentrations.

In contrast to the models discussed above that explain the enhanced strength of metallic alloys containing GB solute segregations by the restraining effect of the segregations on dislocation nucleation at GBs, Turlo and Rupert [31] assumed that strength enhancement is also determined by the effect of segregations on dislocation propagation across grains. Their assumption is based on the results of their atomistic simulations of plastic deformation of $\mathrm{Cu}$ bicrystals containing $\mathrm{GB}$ segregations of $\mathrm{Zr}$. They compared propagation of dislocations in structures with three different types of GBs (Fig. 4). Namely, clean grain boundaries (CGBs) without any solute atoms, GBs containing periodic distribution of solute atoms or, as they call it, ordered grain boundary complexion (OGBC) and amorphous intergranular films (AIF), characterized by very high concentration of solute atoms. According to the simulations [31], the critical stress for dislocation nucleation at GBs decreases, and the critical stress for dislocation propagation across a grain increases owing to the presence of $\mathrm{Zr}$ segregations. Comparing their simulation results with this experimental data [24], Turlo and Rupert [31] concluded that the rate-limiting deformation mechanism in nanocrystalline $\mathrm{Cu}-\mathrm{Zr}$ alloys is dislocation pinning by GB segregations during dislocation propagation.

The results of other computer simulations [32-35] indicate that the strengthening effect of GB segregations depends strongly on the lattice mismatch of solute and matrix atoms as well as on the plastic deformation mechanisms. For instance, Vo et al. [34] revealed in the simulations a considerable increase in the yield strength of nanocrystalline $\mathrm{Cu}$ alloys due to $\mathrm{GB}$ solute segregations, which scaled linearly with the lattice mismatch of the solute and matrix atoms (Fig. 5). This result was later confirmed experimentally [25].

Babicheva et al. [33] demonstrated in the molecular dynamics simulations a moderate increase of the yield strength of nanocrystalline $\mathrm{Al}$ due to GB Co segregations
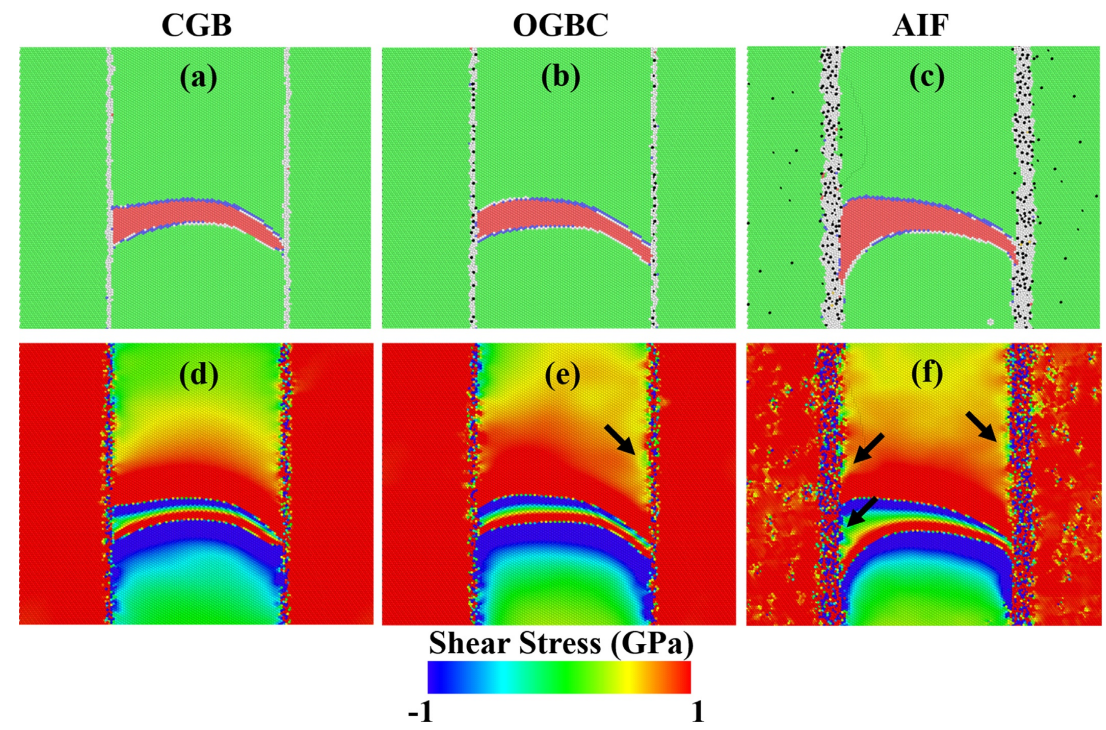

Fig. 4. $(\mathrm{a}-\mathrm{c})$ Local atomic structure and $(\mathrm{d}-\mathrm{f})$ atomic shear stress distribution during dislocation propagation simulations in $\mathrm{Cu}-\mathrm{Zr}$ alloy at 3\% applied shear strain. Black arrows denote local regions of low stress. Reproduced from [31] with permission. Copyright (2018), Elsevier. 


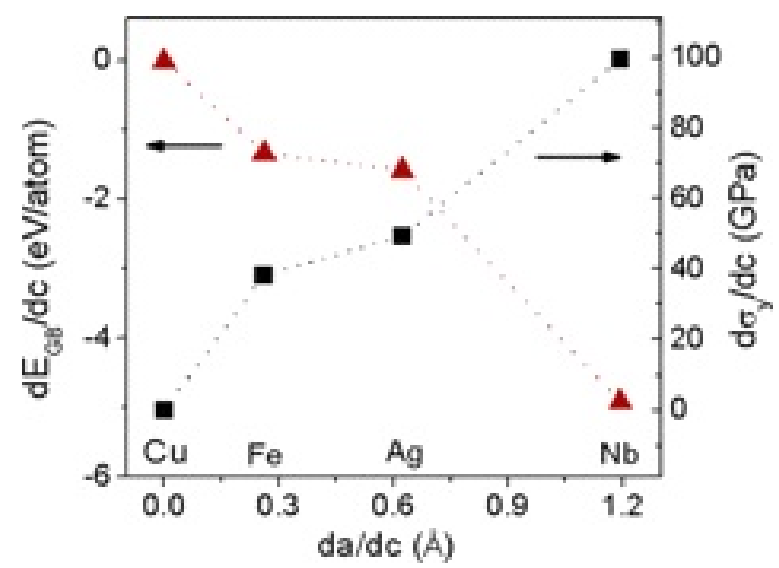

Fig. 5. Linear relationships between lattice mismatch of solute and matrix atoms vs GB energy and yield strength of nc Cu samples. Reproduced from [34] with permission. Copyright (2011), Elsevier.

and the absence of the strengthening effect for $\mathrm{Mg}$ segregations. Moreover, earlier atomistic simulations [35] showed that GB Pb segregations reduce the yield strength of nanocrystalline Al. In both cases, the simulations demonstrated that room-temperature deformation of nanocrystalline $\mathrm{Al}$ (containing $\mathrm{Mg}$ or $\mathrm{Pb}$ segregations) occurs via GB sliding or GB sliding coupled with GB migration. Therefore, one can conclude that although GB Pb segregations hamper lattice dislocation slip, these can promote GB sliding, and enhanced GB sliding leads to a decrease in the yield strength.

Bobylev et al. [36] recently developed theoretical model explaining experimentally observed enhanced strength of UFG alloys containing GB segregations. Unlike previous models it takes into account not only concentration of the solute but also a shape and size of segregations. In the framework of proposed model segregations were treated as the coherent ellipsoidal inclusions dispersed in the random way over GBs (Fig. 6a). The ellipsoidal shape (characterized by half axes $a_{1}$, $a_{2}$, and $a_{3}$; see Fig. 6b) of the inclusions was chosen as a good approximation for a range of actual segregation shapes (spheres, ellipsoids, plates) observed, in particular, in UFG Al alloys [14-19]. The difference between the solute concentrations $c_{s}$ and $c_{m}$ inside and outside the inclusions, respectively, leads to a change of the lattice parameter $a_{s s}$ of the inclusions:

$a_{s} \approx a_{m}+100\left(c_{s}-c_{m}\right) \Delta a$,

where $a_{m}$ is the matrix lattice parameter and $\Delta a$ is the change of the lattice parameter of the alloy associated with an increase of the solute concentration by 0.01 (that is, by 1 at.\%). As a result, an internal strain (eigenstrain) is created inside the inclusions. Assuming the dilatational character of eigenstrain, the eigenstrain tensor $\varepsilon_{i j}^{*}$ is written as

$\varepsilon_{i j}^{*}=\varepsilon^{*} \delta_{i j}$,

where $i, j=1,2,3, \delta_{i j}$, is the Kronecker delta, and $\varepsilon_{i j}^{*}$ is the lattice mismatch between the inclusion and the matrix, defined as

$\varepsilon^{*}=\frac{a_{s}-a_{m}}{a_{m}}$.

In the exemplary case of $\mathrm{Al}$ alloy 1570 the value of $\varepsilon^{*}$ was found to be $\sim 0.01$, which is low enough to provide the coherency of the matrix-inclusion interface.

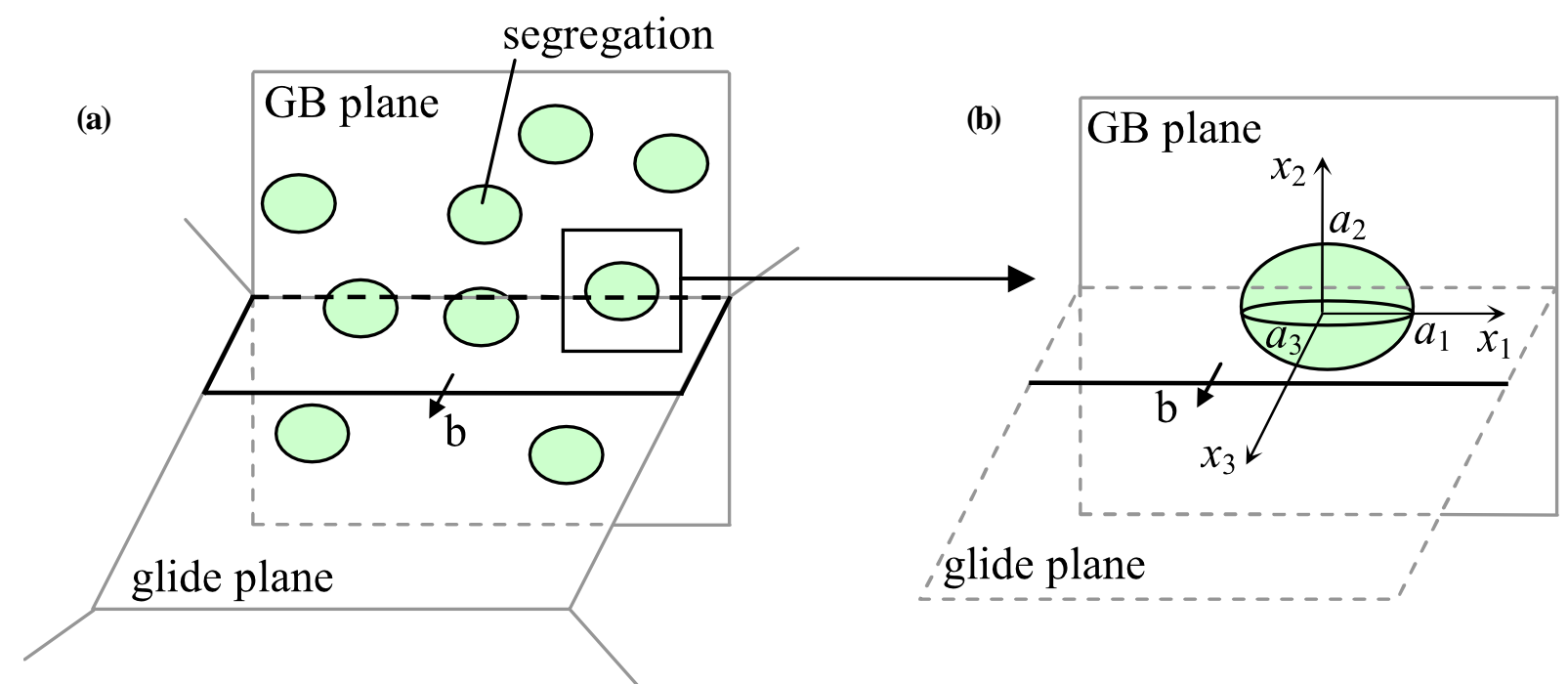

Fig. 6. (a) Grain boundary with randomly dispersed segregations (green ovals) and dislocation that nucleated at the same grain boundary. (b) Magnified inset showing a single ellipsoidal inclusion with a dislocation line in its vicinity. Reproduced from [36] with permission. Copyright (2019), Elsevier. 


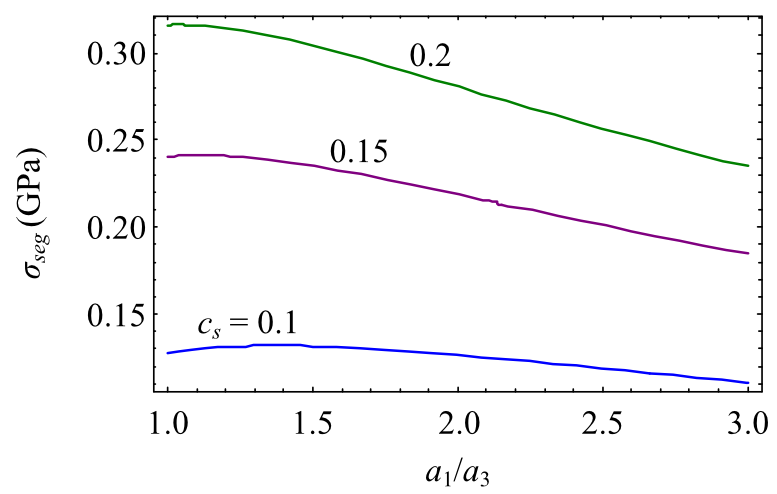

Fig. 7. Dependences of the segregation contribution $\sigma_{\text {seg }}$ to the yield stress of Al alloy 1570 on the segregation aspect ratio $a_{1} / a_{3}$, calculated under the assumption that the average solute concentration $\bar{c}_{g b}$ in the GB layer is constant, for $c_{m}=0.064, \bar{c}_{g b}=0.073, c_{s}=0.1,0.15$, and 0.2 .

Due to internal strain each ellipsoidal inclusion produces an elastic stress field that creates forces acting on dislocation segments in its vicinity and can prevent their emission from GBs by pinning them immobile. To overcome these forces external stress must by increased by some value $\sigma_{\text {seg }}$. Using theory of dislocation and inclusions Bobylev et al. [36] calculated dependences (Fig. 7 ) of the value $\sigma_{\text {seg }}$ on aspect ratio $a_{1} / a_{3}$ (it was assumed $a_{1}=a_{2}$ ) of the inclusion in the exemplary case of $\mathrm{Al}$ alloy 1570 with $\mathrm{Mg}$ GB segregations using following values of parameters (corresponding to experimentally measured $[15,16]$ values): $c_{m}=0.064, \bar{c}_{g b}=0.073, a_{3}=5 \mathrm{~nm}$, $c_{s}=0.1,0.15$, and 0.2 , where $\bar{c}_{g b}$-average solute concentration inside GB (assumed to be constant). From Fig. 7 it is seen that in the case of the constant concentration $\bar{c}_{g b}$ stress $\sigma_{\text {seg }}$ reaches maximum at low aspect ratio values $a_{1} / a_{3}$ (approximately 1.0-1.4 depending on concentration $c_{s}$ ) and then decreases. This means that small spherical or nearly spherical segregations provide higher strengthening compared to elongated ellipsoidal segregations. Also Fig. 7 shows that increase in concentration $c_{s}$ leads to higher values of $\sigma_{\text {seg }}$. The model [36] allows making a conclusion that maximum strengthening due to GB solute segregations is achieved when solute atoms are accumulated in small concentrated clusters as opposed to spreading uniformly over GBs. As it follows from Fig. 7 the value of $\sigma_{\text {seg }}$ at $c_{s} \approx 0.15$ is close to experimentally measured strengthening of alloy 1570 equal to $200 \mathrm{MPa}$ [16]. Thus proposed model agrees relatively well with the experiment.

In conclusion, the results of experiments and simulations demonstrated that GB solute segregations tend to increase the yield strength of UFG and NC alloys. Experimental and theoretical data points to two possible mechanisms of GB segregation induced strength enhancement: (1) suppression of dislocation emission from GBs and (2) suppression of dislocation slip through grain by pinning or elastic interaction between dislocations and GB segregation. It seems that both types of mechanisms are possible and their effectiveness depends on the crystal structure and chemical composition of material. The suppression of dislocation emission most likely requires realization of specific atomic structures, so this mechanism is unlikely to be universal and effective in any type of material. Similarly, suppression of dislocation slip should be more pronounced in the materials where solute atoms produce noticeable lattice parameter change, thus producing relatively high elastic stresses interacting with moving dislocations. At the same time, if solute atoms do not affect lattice parameter this mechanism should be ineffective. Recent findings by Bobylev et al. [36] indicate that if strengthening is controlled by elastic interaction between GB solute segregations and lattice dislocations then the maximum strengthening of an alloy is achieved by the formation of GB solute segregations in the form of small concentrated clusters, instead of homogeneous distribution of solutes over GBs.

\section{REFERENCES}

[1] I.A. Ovid'ko, R.Z. Valiev, and Y.T. Zhu, Review on superior strength and enhanced ductility of metallic nanomaterials, Prog Mater Sci, 2018, vol. 94, pp. 462-540. https://doi.org/10.1016/ j.pmatsci.2018.02.002

[2] I.A. Ovid'ko and A.G. Sheinerman, Grain boundary sliding, triple junction disclinations and strain hardening in ultrafine-grained and nanocrystalline metals, Int J Plasticity, 2017, vol. 96, pp. 227-241. https://doi.org/10.1016/ j.ijplas.2017.05.005

[3] Y. Estrin and A. Vinogradov, Extreme grain refinement by severe plastic deformation: A wealth of challenging science, Acta Mater, 2013, vol. 61, no. 3, pp. 782-817. https://doi.org/10.1016/ j.actamat.2012.10.038

[4] A. Vinogradov and Y. Estrin, Analytical and numerical approaches to modelling severe plastic deformation, Prog Mater Sci, 2018, vol. 95, pp. 172-242. https://doi.org/10.1016/ j.pmatsci.2018.02.001

[5] J. Liu, A.S. Khan, L. Takacs, and C.S. Meredith, Mechanical behavior of ultrafine-grained/ nanocrystalline titanium synthesized by mechanical milling plus consolidation: Experiments, modeling and simulation, Int. J. Plast., 2015, vol. 64, pp. 151-163. https://doi.org/ 10.1016/j.ijplas.2014.08.007 
[6] I.C. Choi, D.H. Lee, B. Ahn, K. Durst, M. Kawasaki, T.G. Langdon, and J.I. Jang, Enhancement of strain-rate sensitivity and shear yield strength of a magnesium alloy processed by high-pressure torsion, Scr. Mater., 2015, vol. 94, pp. 44-47. https:/ /doi.org/10.1016/j.scriptamat.2014.09.014

[7] Y. Aoyagi, T. Tsuru, and T. Shimokawa, Crystal plasticity modeling and simulation considering the behavior of the dislocation source of ultrafine-grained metal, Int. J. Plast., 2014, vol. 55, pp. 43-57. https://doi.org/10.1016/ j.ijplas.2013.09.009

[8] A.S. Khan and J. Liu, A deformation mechanism based crystal plasticity model of ultrafinegrained/nanocrystalline FCC polycrystals, Int. J. Plast., 2016, vol. 86, pp. 56-69. https://doi.org/ 10.1016/j.ijplas.2016.08.001

[9] Z.C. Cordero, B.E. Knight, and C.A. Schuh, Six decades of the Hall-Petch effect - a survey of grain-size strengthening studies on pure metals, Int. Mater. Rev., 2016, vol. 61, no. 8, pp. 495-512. https://doi.org/10.1080/09506608.2016.1191808

[10] Y. Li, A.J. Bushby, and D.J. Dunstan, The HallPetch effect as a manifestation of the general size effect, Proc. Royal Soc. Lond. A, 2016, vol. 472, no. 2190, pp. Art. no. 20150890. https:// doi.org/10.1098/rspa.2015.0890

[11] E.N. Hahn and M.A. Meyers, Grain-size dependent mechanical behavior of nanocrystalline metals, Mater. Sci. Eng. A, 2015, vol. 646, pp. 101-134. https://doi.org/10.1016/ j.msea.2015.07.075

[12] L. Tian, A short review on mechanical behavior of nanocrystalline materials, Int. J. Metall. Met. Phys., 2017, vol. 2, no. 1, pp. 2008-1 - 2008-13. https://doi.org/10.35840/2631-5076/9208

[13] R.W. Armstrong, Dislocation pile-ups, strength properties and fracturing, Rev. Adv. Mater. Sci., 2017, vol. 48, no. 1, pp. 1-12. http://www.ipme.ru/ e-journals/RAMS/no_14817/

01_14817_armstrong.pdf

[14] X. Sauvage, A. Ganeev, Y. Ivanisenko, N. Enikeev, M. Murashkin, and R. Valiev, Grain Boundary Segregation in UFG Alloys Processed by Severe Plastic Deformation, Adv. Eng. Mater., 2012, vol. 14, no. 11, pp. 968-974. https://doi.org/10.1002/ adem.201200060

[15] X. Sauvage, N. Enikeev, R. Valiev, Y. Nasedkina, and M. Murashkin, Atomic-scale analysis of the segregation and precipitation mechanisms in a severely deformed Al-Mg alloy, Acta Mater., 2014, vol. 72, pp. 125-136. https://doi.org/10.1016/ j.actamat.2014.03.033
[16] R.Z. Valiev, N.A. Enikeev, M.Y. Murashkin, V.U. Kazykhanov, and X. Sauvage, On the origin of the extremely high strength of ultrafine-grained Al alloys produced by severe plastic deformation, Scr. Mater., 2010, vol. 63, no. 9, pp. 949-952. https://doi.org/10.1016/ J.Scriptamat.2010.07.014

[17] P.V. Liddicoat, X.Z. Liao, Y. Zhao, Y. Zhu, M.Y. Murashkin, E.J. Lavernia, R.Z. Valiev, and S.P. Ringer, Nanostructural hierarchy increases the strength of aluminium alloys, Nat. Commun., 2010, vol. 1, pp. 63. https://doi.org/10.1038/ ncomms 1062

[18] R.Z. Valiev, N.A. Enikeev, and T.G. Langdon, Towards superstrength of nanostructured metals and alloys, produced by SPD, Kovove Mater., 2011, vol. 49, no. 1, pp. 1-9. https://doi.org/ 10.4149/km_2011_1_1

[19] R.Z. Valiev, M.Y. Murashkin, A.V. Ganeev, and N.A. Enikeev, Superstrength of nanostructured metals and alloys produced by severe plastic deformation, Phys. Metals Metallogr., 2012, vol. 113, no. 13, pp. 1193-1201. https://doi.org/10.1134/ s0031918x12130042

[20] M.M. Abramova, N.A. Enikeev, R.Z. Valiev, A. Etienne, B. Radiguet, Y. Ivanisenko, and X. Sauvage, Grain boundary segregation induced strengthening of an ultrafine-grained austenitic stainless steel, Mater. Lett., 2014, vol. 136, pp. 349-352. https://doi.org/10.1016/ j.matlet.2014.07.188

[21] G. Sha, K. Tugcu, X.Z. Liao, P.W. Trimby, M.Y. Murashkin, R.Z. Valiev, and S.P. Ringer, Strength, grain refinement and solute nanostructures of an Al-Mg-Si alloy (AA6060) processed by high-pressure torsion, Acta Mater., 2014, vol. 63, pp. 169-179. https://doi.org/10.1016/ j.actamat.2013.10.022

[22] J.G. Kim, N.A. Enikeev, J.B. Seol, M.M. Abramova, M.V. Karavaeva, R.Z. Valiev, C.G. Park, and H.S. Kim, Superior Strength and Multiple Strengthening Mechanisms in Nanocrystalline TWIP Steel, Sci. Rep., 2018, vol. 8, no. 1, pp. 11200. https://doi.org/10.1038/s41598-018-29632-y

[23] S. Takaki, D. Akama, N. Nakada, and T. Tsuchiyama, Effect of Grain Boundary Segregation of Interstitial Elements on HallPetch Coefficient in Steels, Mater. Trans., 2014, vol. 55, no. 1, pp. 28-34. https://doi.org/10.2320/ matertrans.MA201314

[24] A. Khalajhedayati, Z.L. Pan, and T.J. Rupert, Manipulating the interfacial structure of nanomaterials to achieve a unique combination 
of strength and ductility, Nat. Commun., 2016, vol. 7, pp. Art. no. 10802. https://doi.org/10.1038/ ncomms 10802

[25] S. Ozerinc, K.P. Tai, N.Q. Vo, P. Bellon, R.S. Averback, and W.P. King, Grain boundary doping strengthens nanocrystalline copper alloys, Scr. Mater., 2012, vol. 67, no. 7-8, pp. 720723. https://doi.org/10.1016/j.scriptamat. 2012.06.031

[26] P. Zhang, J.Y. Zhang, J. Li, G. Liu, K. Wu, Y.Q. Wang, and J. Sun, Microstructural evolution, mechanical properties and deformation mechanisms of nanocrystalline $\mathrm{Cu}$ thin films alloyed with Zr, Acta Mater., 2014, vol. 76, pp. 221-237. https://doi.org/10.1016/ j.actamat.2014.04.041

[27] H. Jia, R. Bjřrge, L. Cao, H. Song, K. Marthinsen, and Y. Li, Quantifying the grain boundary segregation strengthening induced by postECAP aging in an Al-5Cu alloy, Acta Mater., 2018, vol. 155, pp. 199-213. https://doi.org/ 10.1016/j.actamat.2018.05.075

[28] M. Rajagopalan, K. Darling, S. Turnage, R.K. Koju, B. Hornbuckle, Y. Mishin, and K.N. Solanki, Microstructural evolution in a nanocrystalline CU-Ta alloy: A combined in-situ TEM and atomistic study, Mater. Des., 2017, vol. 113, pp. 178-185. https://doi.org/https://doi.org/10.1016/ j.matdes.2016.10.020

[29] K.I. Chang and S.I. Hong, Effect of sulphur on the strengthening of a $\mathrm{Zr}-\mathrm{Nb}$ alloy, J. Nucl. Mater., 2008, vol. 373, no. 1-3, pp. 16-21. https://doi.org/ 10.1016/j.jnucmat.2007.04.045

[30] V. Borovikov, M.I. Mendelev, and A.H. King, Solute effects on interfacial dislocation emission in nanomaterials: Nucleation site competition and neutralization, Scr. Mater., 2018, vol. 154, pp. 12-15. https://doi.org/10.1016/j.scriptamat. 2018.05.011
[31] V. Turlo and T.J. Rupert, Grain boundary complexions and the strength of nanocrystalline metals: Dislocation emission and propagation, Acta Mater., 2018, vol. 151, pp. 100-111. https:// doi.org/10.1016/j.actamat.2018.03.055

[32] V. Borovikov, M.I. Mendelev, and A.H. King, Effects of solutes on dislocation nucleation from grain boundaries, Int. J. Plast., 2017, vol. 90, pp. 146-155. https://doi.org/10.1016/j.ijplas. 2016.12.009

[33] R.I. Babicheva, S.V. Dmitriev, L. Bai, Y. Zhang, S.W. Kok, G. Kang, and K. Zhou, Effect of grain boundary segregation on the deformation mechanisms and mechanical properties of nanocrystalline binary aluminum alloys, Comput. Mater. Sci., 2016, vol. 117, pp. 445-454. https://doi.org/10.1016/j.commatsci.2016.02.013

[34] N.Q. Vo, J. Schafer, R.S. Averback, K. Albe, Y. Ashkenazy, and P. Bellon, Reaching theoretical strengths in nanocrystalline $\mathrm{Cu}$ by grain boundary doping, Scr. Mater., 2011, vol. 65, no. 8, pp. 660-663. https://doi.org/10.1016/ j.scriptamat.2011.06.048

[35] S. Jang, Y. Purohit, D.L. Irving, C. Padgett, D. Brenner, and R.O. Scattergood, Influence of $\mathrm{Pb}$ segregation on the deformation of nanocrystalline Al: Insights from molecular simulations, Acta Mater., 2008, vol. 56, no. 17, pp. 4750-4761. https://doi.org/10.1016/j.actamat. 2008.05.024

[36] S.V. Bobylev, N.A. Enikeev, A.G. Sheinerman, and R.Z. Valiev, Strength enhancement induced by grain boundary solute segregations in ultrafinegrained alloys, Int. J. Plast., 2019, vol. 123, pp. 133-144. https://doi.org/10.1016/j.ijplas. 2019.07.013 